\title{
LA MÚSICA MEXICANA A TRAVÉS DE SUS CRÓNICAS *
}

\section{Gloria Carmona}

Este trabajo ha sido elaborado con material extraído de periódicos del siglo pasado, cuya riqueza histórica es invaluable para conocer la vida y el desarrollo de la música culta en México.

El material fue elegido de crónicas y gacetillas, indistintamente, en primer lugar porque recién consolidado el periodismo en México los géneros no se advierten fácilmente diferenciables $\mathrm{y}$, en segundo, porque innumerables gacetillas resultan crónicas $-\mathrm{y}$ viceversa-, no tanto por su dimensión cuanto por su estilo y por lo que ilustran. Desde este punto de vista se justifica que el título de este trabajo haya englobado fuentes diversas.

No obstante, a mi modo de ver la crónica es en ese momento nudo de enlace entre la gacetilla, información breve y escueta, y la crónica musical que floreció hacia fines del siglo (prescindamos de la crín tica musical cuya existencia es aún precaria en México). Sin duda fue diferenciándose al afocar ciertos aspectos relevantes de la música o los intérpretes de ella, así como apuntando someros juicios de valor sin que éstos pasaran de meras impresiones subjetivas. Más adelante se volvió verborreica y solemne, y con pretensiones de erudita, aunque, cosa curiosa, la erudición es más literaria que musical. En el cambio perdió la gracia y la vitalidad de las crónicas de "Fidel", por ejemplo, y la frescura e ingenuidad de las gacetillas anónimas -excepción hecha de las crónicas de Gutiérrez Nájera, para quien la música fue sólo el fugaz pretexto de su prosa espléndida.

Lo que verdaderamente importa en este caso es que crónicas y gacetillas configuran la cultura y el espíritu de toda una época y permiten comprender y apreciar la nuestra.

HENRI HERZ Y EL NACIONALISMO MUSICAL MEXICANO

\section{Preámbulo}

Entre los primeros concertistas que visitaron nuestro país en el siglo pasado e inauguraron una época de benéfica influencia exte-

* Primera de dos partes. 
rior, fue sin duda Henri Herz quien llenó un episodio intenso y crucial en el gusto musical de México.

No está por demás decir que las giras de virtuosos e instrumentistas en el ámbito europeo eran vieja costumbre, no sólo por la poca o nula distancia geográfica de una ciudad más o menos importante a otra sino porque el esquema de dichas ciudades, proveniente del antiguo sistema feudal, las convertía en pequeños reinos donde las artes habían floxecido, arraigado y formado una tradición, lo que propiciaba no sólo positivas rivalidades entre uno y otro feudo, sino, lo que es más importante, el intercambio $y$, por consiguiente, el mutuo enriquecimiento. Por las mismas razones, no ocurría lo mismo en el orbe americano, donde aún hoy, fuera de la capital de México, las giras artísticas son rara avis en la provincia.

No obstante, a partir de 1840 se había dejado sentir en México la efímera migración de instrumentistas. El primero de ellos, William Vincent Wallace, violinista y compositor de origen irlandés, había sido recibido calurosamente por la sociedad de México, pues se advierte que sus actuacione no tenían todavía un carácter totalmente público. Sucesivamente, en los años de 1842 y 1844, nos visitaron el violinista Hypolite Larsonneur, el cellista Max Bohery el violinista y compositor Henri Vieuxtemps, con su hermana Fanny.

En 1849 coincidieron en México varios artistas europeos, reunión que no pasó sin los enredos del caso, lo que estimuló la afluencia del grueso del público y llamó su atención hacia aspectos hasta entonces inadvertidos o poco apreciados.

Efectivamente, El Siglo XIX anunció el 16 de junio de ese año la llegada de la cantante británica Ana Bishop, su maestro, el arpista y compositor Charles Bochsa * y el bajo Attilio Valtellina, quienes después de un estira y afloja con la empresa del Teatro Nacional dieron su primer concierto un mes más tarde.

Por la crónica de "Fidel", seudónimo de Guillermo Prieto, aparecida en las páginas de $E l$ Siglo $X I X,{ }^{1}$ advertimos que no obstante la cortesía, la Bishop no fue totalmente del agrado del público mexicano:

* En su obra monumental de la que forma parte El teatro en México en la ëpoca de Santa Anna, Luis Reyes de la Maza consigna erróneamente el nombre de este compositor, Robert Nicolas Charles Bochsa, como Juan Boscha.

1 Julio 17. 
La voz de la Sra. Bishop tiene en nuestro concepto pocas esferas, especialmente bajas, ni es tan argentina ni tan extensa, ni' tan sonora, como las de otras actrices, nacionales y extrangeras que hemos oído, y no obstante la gracia de la encantadora Ana, parece una voz que declina. La educación de esa voz es divina, su escuela correctísima, su vocalización de un mérito superior. Hiere las notas altas con una facilidad y un atrevimiento inimitable; pero no así las bajas, en las que hemos oído sobresalir a la Albini, la Castellán y la Passi.

No podia ser de otra manera si se infiere por la noticia biográfica de la Bishop ${ }^{2}$ que el resorte de la cantante exa el oratorio y el lied, pertenecientes al género lírico, propiamente de cámara, esto es, refinado, íntimo, no sólo en su expresión sino en su ámbito sonoro y que "guiada y formada por Bochsa, que en aquella época, estando a la cabeza de la ópera italiana en Londres, dirigía a los cantantes", había dado un viraje hacia el género operístico o dramático en que estaba habituado el público mexicano y que, por su propio carácter, requiere de una mayor exageración y volumen en su expresión. Bochsa no tuvo mejor suerte, pues siguiendo a "Fidel", "más pudimos admixar el talento creador del artista que "al Paganini del arpa" ", lo cual, dicho sea de paso, refleja el gusto por la acrobacia, por el espectáculo en sí mismo.

"A mí me parece con justicia -continúa "Fidel"- que el Sr. Bochsa más tocó para los inteligentes en esta primera vez que para nos, los del vulgo ignorante."

No obstante, en su segunda intervención en el programa:

... y a los acentos de su arpa, correspondieron los signos de la más viva aprobación. ¡Sobre que se trataba de un sonecito del país! [El Ahualulco!, pero embellecido, esforzado por el gran compositor: todo un fandango tenía yo en la cabeza; Ia china zalamera, su cuerpecito gentil, el zapateo de su sujeto; todo se me representaba animado, travieso y subversivo: después eran Los puritanos, con sus entonaciones fogosas; después los enanos con todo su ridículo y chiste musical. Entonces a nos, los del vulgo, ignorante, nos hablaba el arpa en su idioma vulgar, picaresco; venía a retozar con los espectáculos que de ocultis amamos, como el español ama sus bailes de candil y el francés su cancán extremoso. El arpa se nacionalizó; pero tan festiva, tan diestra y tan dulce, que ya parecía un piano, ya una flauta,

2 El Siglo XIX, junio 16. 
ya los tonos llenos de un órgano, ya la bulliciosa jaranita de un fandango.

No era nueva esta oleada de música popular en un epectáculo. A decir verdad, durante todo el siglo xvirr los sonecitos y bailes del países se intercalaban en los intermedios de las comedias del Coliseo, así como parece ser verdad que la tonadilla escénica -de extracción popular en España como contrapeso a la influencia de la música y géneros franceses durante la regencia borbónica- habia tenido un enorme auge en las provincias novohispanas, precisamente a causa de que, siguiendo el mismo esquema, permitía la transposición de tipos, costumbres y música locales. Sin embargo, dichas prácticas habían sido decididamente perseguidas por el gobierno virreinal, al identificarlas con el espíritu de la insurgencia, y finalmente postergadas ante el empuje de una moda reciente, culta y de buen gusto entonces: la ópera italiana.

Bochsa tampoco era el primero en colocar la música vernácula del país al lado de la música europea culta. Cinco años antes, Bohrer se le había adelantado al incluir en sus prgoramas una Fantasía sobre sonecitos populares mexicanos. ${ }^{3}$ Pero ni Bochsa ni Bohrer tuvieron la personalidad y brillantez suficientes, ni el arpa ni el cello eran los instrumentos adecuados para producir en el público el impacto deseado. Lo que sí resulta un hecho insólito es que ambos intentan por primera vez en México integrar la música popular del país a las formas y procedimientos de la música culta.

En rigor, ese trasiego constituye un fenómeno que se produce intermitentemente en el acontecer de la música occidental. Una observación más detenida en este sentido podría tal vez aclarar las circunstancias precisas por las que dicho fenómeno se produce. No es el propósito ahondar aquí en estas cuestiones. El hecho es que entre las particularidades que el romanticismo europeo había traído consigo -y era plena época romántica--, estaba precisamente la del consciente retorno a los valores originarios o folklóricos de un país. Chopin con sus polonesas y mazurkas, Liszt con sus rapsodias húngaras (Sshumann con sus lieder), habían iluminado las salas de

3 Otto Mayer Serra en su Panorama de la música mexicana consigna el año de 1841 como fecha de composición de las Variaciones sobre el tema del jarabe mexicano, de José Antonio Gómez (1805-1870); pero no he tenido la ocasión de conocer la partitura ni de alguna manera verificar la fecha de composición. 
concierto europeas, y probablemente su aspecto nacionalista se olvida fácilmente ante su incontestable calidad como compositores. Sus seguidores sólo adoptaron los recursos accesorios y más superficiales de éste, pues no constituyendo obras de creación en sí, producían composiciones de una flagrante hibridez que permitían la liga de uno o varios temas populares, incluso de diversos géneros y procedencias para gestar inacabables potpourrís.

Pero el nacionalismo musical debía tener en México un doble significado; es decir: no sólo el carácter de una escuela o tendencia estética cuanto el afán de una expresión definitoria de una nacionalidad recién adquirida y largamente proclamada como ajeno sentir de país colonizado. En busca de esta expresión, las fórmulas más pedestres del nacionalismo musical venían a la medida para producir un jubiloso narcisismo, ese retozo con lo que de ocultis amamos, como decía "Fidel", y fue sin duda Henri Herz quien lo puso de moda.

\section{La historia}

Para el 6 de julio, quince días después del arribo de Bochsa y la Bishop, El Siglo XIX comunicó a sus lectores que el pianista Herz llegaría en breve a la ciudad de México. A decir de Olavarría, ${ }^{4}$ el nombre y las obras de Herz eran conocidas en México entre aficionados y profesores, y con seguridad así era, si se advierte que nueve años antes Wallace había incluido en su programa una obra de este compositor.

La pomposa noticia biográfica que apareció en el mismo periódico ${ }^{5}$ sacada de la Galería de notabilidades contemporáneas por Cormanin, presentaba a Herz como:

De estatura más que mediana, de un porte elegante, de modales distinguidos, y sin ser en todo rigor buen mozo, tiene un exterior muy agradable, y cada movimiento suyo respira nobleza ... vive en París consagrado a sus amigos. Almuerza con Eugenio Sue, come con Balzac, discute con Julio Janin, discurre con Alejandro Dumas, y todos viven con él en la más estrecha amistad. Su casa está montada con un lujo de príncipe: sus caballos rivalizan con los de Mr. Rotchild,

\& Olavarría y Ferrari, Reseña histórica del teatro... p. 485.

5 El Siglo $X I X$, julio 18. 
y la flor de la sociedad parisiense se disputa las invitaciones a sus tertulias. De sus obras han sacado sus inspiraciones casi todos los compositores de la última época, y en su escuela se han formado Liszt, Thalberg... a quienes ha dado consejos, y con razón se le ha llamado el primer profesor del mundo... Enrique Herz es el más rico de todos los compositores, porque cada una de sus composiciones se paga con ocho o diez mil francos; pero hace noble uso de su fortuna. Como París carecía de una sala de conciertos, mandó construir una a sus expensas, en su hotel, que ha costado millón y medio y que es casi tan célebre como su fundador. Es al mismo tiempo director de la fábrica real de pianos de todas hechuras y tamaños, la cual da ocupación a más de cuatrocientos trabajadores.

Por su parte, Manuel Payno lo presentaba como un personaje legendario en la extensa nota, "Rosario de anécdotas", que publica en el Album Mexicano. ${ }^{6}$

¿Pero quién era en realidad Henri Herz? Con su característico laconismo de estilete los diccionarios de música consignan la siguiente ficha: Heinrich Herz nació en Viena en 1803 y murió en París en 1888. En 1816 entró al Conservatorio de París a estudiar con Prahder y obtuvo el primer premio de piano en 1818. Gozó de una enorme reputación en París, tanto como escritor como maestro, y se dice que sus composiciones atrajeron tres o cuatro veces los premios que hubieran merecido compositores mejores. En 1831 hizo una gira por Alemania con el violinista Lafont, habiendo causado éste una mejor impresión. Visitó Londres en 1833, tocó con la Filarmónica y dio un concierto con sus propias obras, tocando a cuatro manos con Moscheles y Gramer. Nombrado profesor de piano en el Conservatorio de París en 1842, regresó a Inglaterra al año siguiente, abarcando en su gira Edinburgo y Dublín. Por esta época se unió al constructor de pianos Klepfa, en París, pero la especulación fracasó y Herz perdió mucho dinero. Entonces decidió establecer una fábrica de su propiedad y para reparar las pérdidas y obtener el capital necesario hizo una gira por los Estados Unidos, México y Sudamérica que se inició en 1845 y terminó en 1851. Herz dejó ocho conciertos para piano y orquesta y otras composiciones para ese instrumento que suman más de doscientas, incluyendo numerosas variaciones y estudios, así como un método completo para piano.

6 Tomo II, 1849. 
Con Liszt, Thalberg, Pixis, Czerny y Chopin contribuyó al Hexamerón, o sea, una serie de seis variaciones sobre la Marcha de Los puritanos de Bellini. En 1837 en un concierto de caridad en París, estas notabilidades se sentaron cada una en su propio piano y tocaron por turno su variación, siendo Liszt quien improvisara una introducción, un final y los enlaces entre una y otra. Eran prodigiosas su brillantez, fuerza y bravura en su interpretación, si bien no se fincaban en cualidades más sólidas. Herz encontró lo que gusta al público y paga por ello. "¿No es prejuicioso Herz -decía Mendelssohn- cuando afirma que los parisienses sólo pueden entender y apreciar las variaciones?"' Schumann nunca se cansó de burlarse de sus pretensiones y sus piezas. Su Gesammelte Schriften contiene muchas crónicas, todas ellas escritas en el mismo estilo irónico. De hecho, Herz fue condenado al olvido inmediato.

La noticia de la llegada de Herz a México fue muy comentada. Los músicos mexicanos, encabezados por Joaquín María Aguilar y José María Chávez, suscriben en El Sigo XIX y en El Monitor Republicano ${ }^{7}$ una invitación general que titulan: "Trofeo musical Henri Herz", para ir al encuentro de tan distinguido visitante al Peñón Viejo. El propio Monitor Republicano en su edición del 13 de julio, hace la reseña del recibimiento: a las dos y media de la tarde la comitiva compuesta por muchos artistas y personas particulares salió en gran número de coches del Hotel del Bazar y se dirigió a la garita donde había de entrar la diligencia que conducía a Herz. Después de una espera considerable se avisó que el de la diligencia se negaba a parar como se le dijo, so pretexto de que habiendo remudado en la posta anterior no había motivo para ello, por lo que la comitiva atravesó sus coches en el camino para impe-dirle el paso. A su llegada, el cochero no tuvo más remedio que detenerse, no sin antes dejar muy claro que no se hacía responsable de la multa que por ello la dirección le impusiese. De esta manera, Herz pudo ser llevado por sus admiradores a su hospedaje en el Hotel de la Gran Sociedad, y con la grata impresión aún reciente agradeció la calurosa bienvenida por medio de una carta escrita en elegante estilo, salpicado de giros a la francesa, que publicaron El Siglo XIX y El Monitor Republicano en sus ediciones respectivas del 12 y 14 de ese mes:

7 Julio 10. 
Desde Europa - dice adulador- me era conocida la extraordinaria afición que tienen los generosos mexicanos a las artes, y en especial a la música; y considero la recepción de hoy menos como una muestra de benevolencia personal, que como un homenaje solemne, tributado al arte divino, del que no soy más que un humilde secretario.

No pasaron inadvertidos para Bochsa la pedantería y el hábil manejo publicitario de que hacía gala Herz y con seguridad temió ver opacado su éxito y su prestigio. Aparentemente aguijoneado por la afirmación inserta al pie de la biografía de Herz de que no existía el Conservatorio de Londres, confió al redactor de El Monitor Republicano los datos que formaron la "Noticia curiosa. E1 Conservatorio Real de Londres", ${ }^{8}$ del que se decía gobernador, esto es, miembro de la junta de gobierno. Ulman, el secretario de Herz, refutó el artículo en airados térmios:

Muy señores míos: He tenido el gusto de ver al Sr. Patiño, quien me ha informado bondadosamente de que el artículo publicado en el Monitor, en que se habla de la academia de música, fue escrito por dicho señor, con arreglo a los datos que le dio Mr. Bochsa.

Estos datos son enteramente falsos (...) El Sr. Patiño nos ha dado muchos testimonios de amistad a Mr. Herz y a mí y estamos seguros de que jamás consentirá a presentarse a cábala mezquina. Noticias falsas y malévolas lo indujeron al error... ${ }^{9}$

A la carta le precedió una noticia contradictoria, pues:

Sabedor Mr. Herz que se había formado una conspiración para silbar

anoche en el teatro a Mr. Bochas, tomó el mayor empeño en que se desistiese de semejante propósito. ${ }^{10}$

Sin duda Patiño tenía razón en su contestación a Ulman, pues:

¿Qué le importa a él (Ulman), sino que haya o no en Londres conservatorio de música, ni que éste sea mejor o peor que el de París? Peregrino en ambos países, en ambos extranjeros, ¿qué motivo plausible puede haber movido a provocar esta ridícula polémica? ¿Qué le importa a México que Bochsa sea o no sea gobernador del conservatorio de Londres, y que Herz sea o deje de ser profe-

8 El Monitor Republicano, julio 27.

a El Siglo XIX, julio 29.

$10 \mathrm{El}$ Siglo $X I X$, julio 20 . 


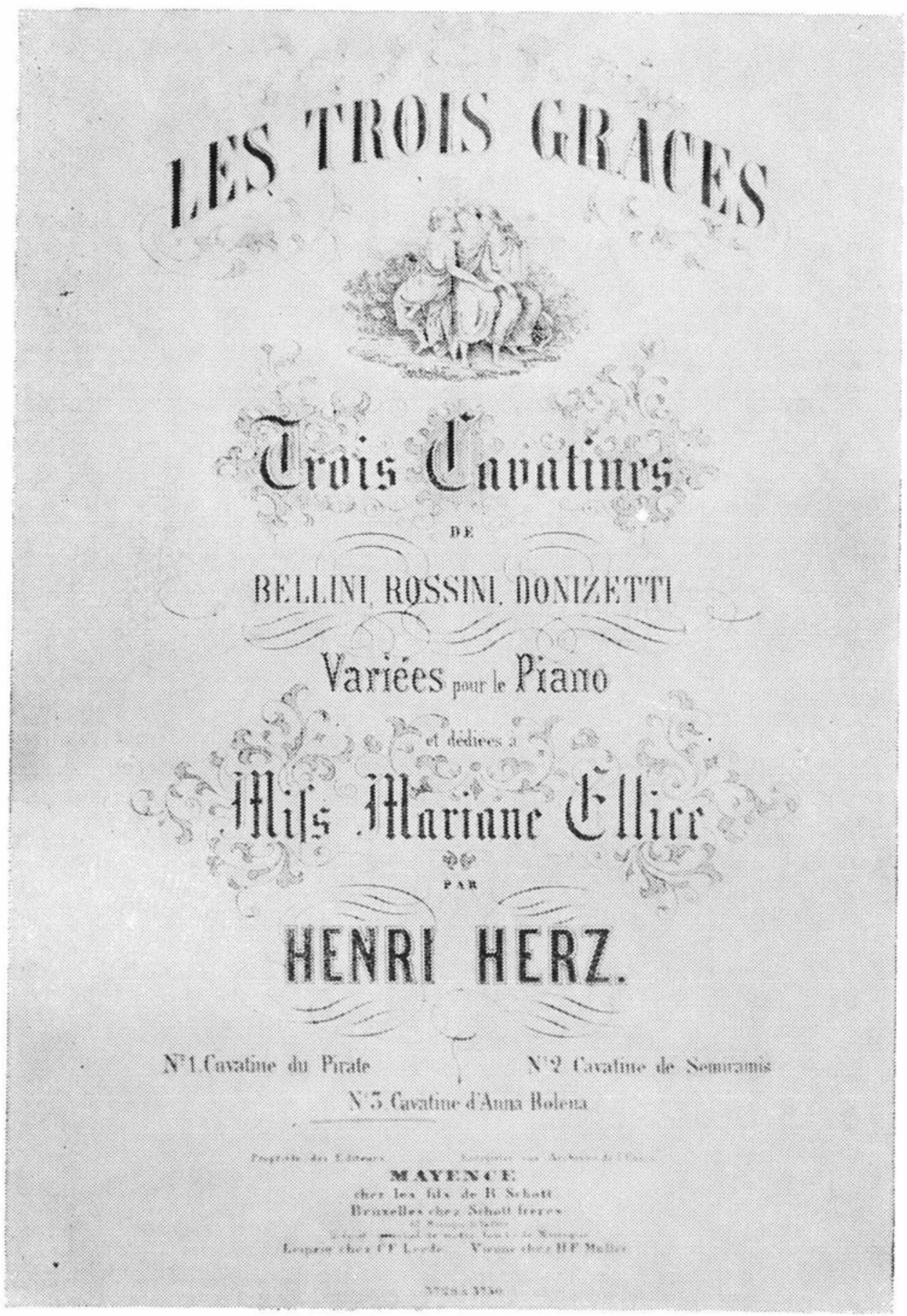


DOI: http://dx.doi.org/10.22201/iie.18703062e.1979.49.1116

\section{L.

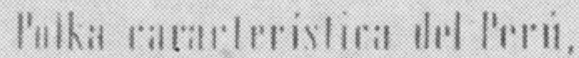

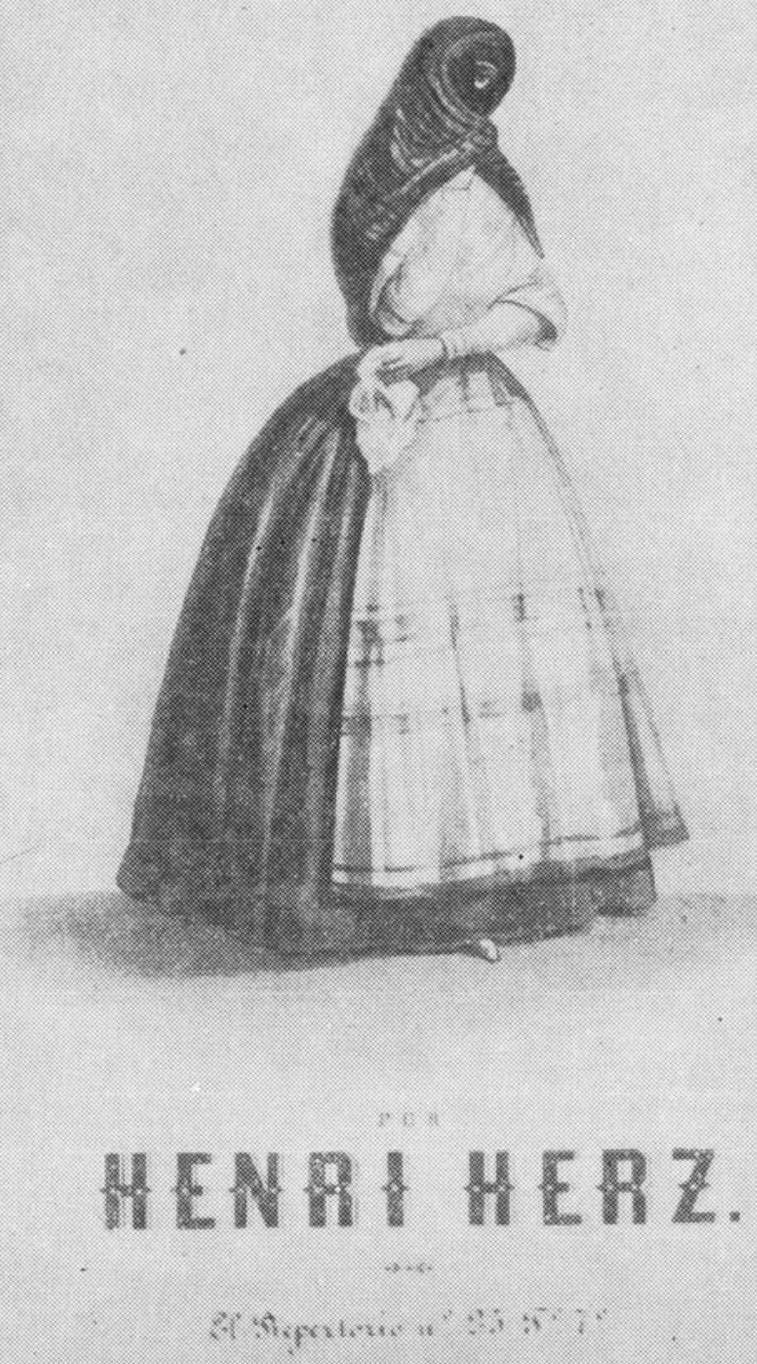




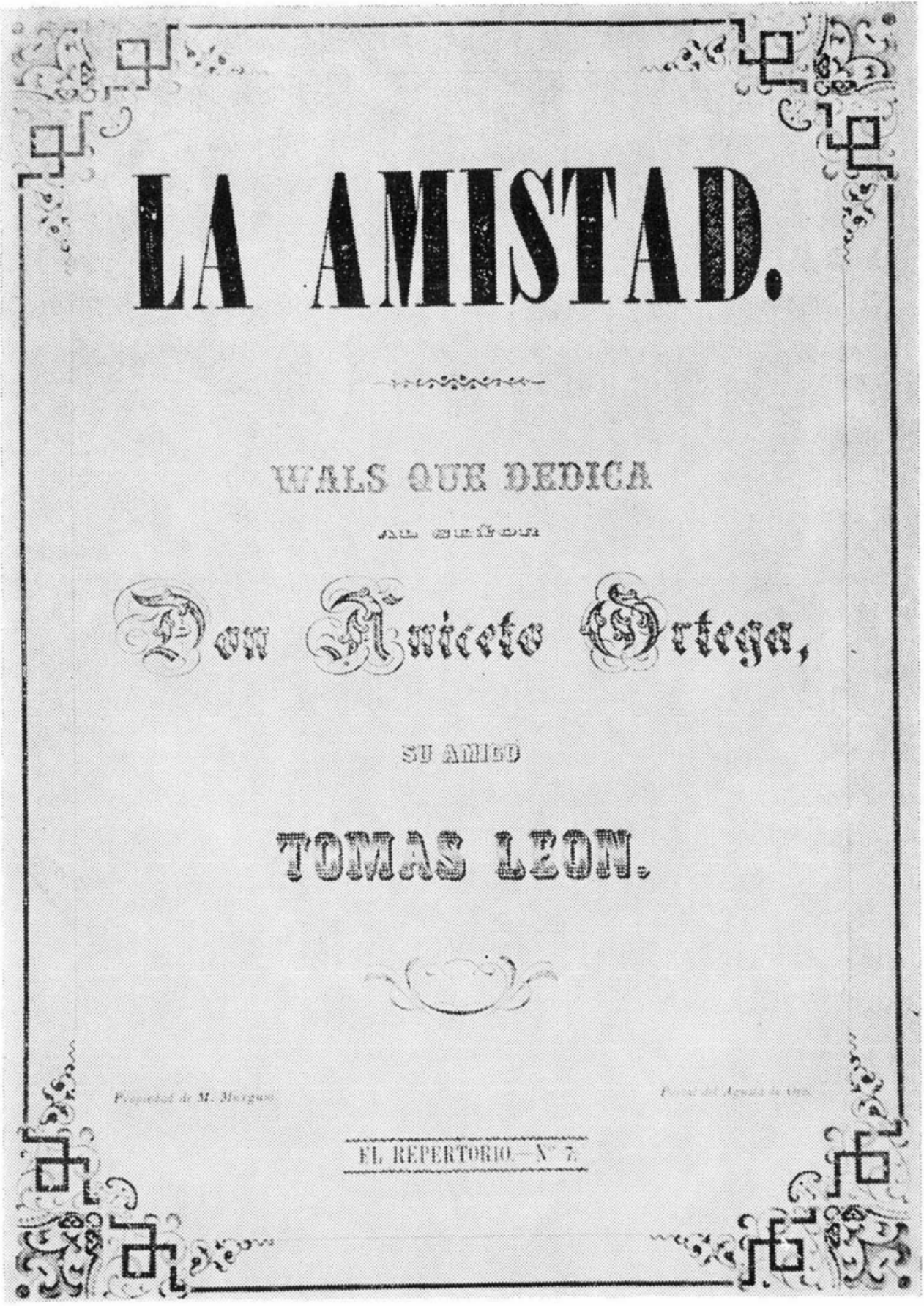


DOI: http://dx.doi.org/10.22201/iie.18703062e.1979.49.1116 
sor del de París, si ambos son unos célebres artistas, si ambos en sus respectivos instrumentos llaman la atención del público y saben arrebatarle con sus bellezas los más estrepitosos aplausos? ${ }^{11}$

Lo que Patiño ignoraba es que se esgrimían cuestiontes más delicadas, pues Bochsa tenía su propia historia: como arpista y compositor apuntaba una carrera de grandes triunfos en París, en donde había sido designado arpista de Napoleón $\mathrm{y}$, posteriormente, de Luis XVIII y del duque de Berry. Sus óperas se habían puesto en la Opéra-Comique entre 1813 y 16; su Requiem a la memoria de Luis XVI se había estrenado con gran solemnidad. No obstante, habiéndose descubierto y denunciado numerosos plagios en sus composiciones había tenido que huir de Francia para nunca volver. En su ausencia fue juzgado y condenado a doce años de prisión y a pagar una multa considerable. En Londres se hizo de un rápido prestigio y sus actividades continuaron. Fue profesor y secretario general de la Royal Academy of Music y director del King's Theatre. En éste sus programaciones contenían siempre un detalle novedoso y de gran impacto sobre el público "no siempre de buen gusto", puntualiza el Grove's Dictionary. Por ejemplo, en uno de ellos había incluido la sinfonía Pastoral de Beethoven acompañada de ilustraciones actualizadas. En el axpa estaba siempre a la búsqueda de nuevos efectos sonoros y se le reconoce como un revolucionario en la técnica de tañer ese instrumento. De todo ello, se colige que Bochsa era un músico de imaginación poco apreciada y nada común, así como un hombre por encima de los convencionalismos en el arte y en la vida. Así lo demostró cuando en 1839 huyó de Londres con la joven esposa del compositor y director inglés, personaje prominente en su época, consagrado sire, Henry Bishop. Son su amante, lady Bishop, había iniciado una larga gira de conciertos que incluía México y terminaría en Sydney, Australia, donde murió poco después, en 1856.

Mientras tanto, encontrándose el Teatro Nacional contratado por Bochsa para sus conciertos y los de la Bishop, Herz hizo una intentona que resultó pretenciosa:

Parece que este ilustre artista trataba de dar su primer concierto en el salón de recepción de palacio; pero una negativa del señor 11 El Monitor Republicano, julio 31. 
presidente * sobre la que se hacen varios comentarios, lo obligó a buscar otro local. 12

No obstante, deseoso de hacerse oír lo antes posible, hace los arreglos necesarios para presentarse en la Lonja, lugar de recreo del grupo aristocratizante que mostró ciertas reticencias, así:

La verdedera causa de las dificultades que había para arreglar el concierto (...) consistía en la fundada repugnancia que había por parte de ciextos suscriptores para que dándose entrada franca a todos tuvieran tal vez sus esposas e hijas que estar junto a personas sin principios, educación y decencia ${ }^{13}$

Pero el "obstáculo" se allanó mediante la venta de boletos intransferibles y titulares, esto es, que ostentaban el nombre del comprador.

Ante semejante presunción era natural que el público se mostrara susceptible y pese a su curiosidad de oír a tan ilustre artista, el primer concierto de éste, celebrado el 6 de agosto en la Lonja, se vio desairado:

La noche estaba fría y lluviosa - dice un comedido comentarista-, y acaso esto tuvo alguna parte en que la concurrencia no fuera muy numerosa aunque en nuestro concepto, la principal causa de ello fue otra, de que no queremos ocuparnos en este momento. Como a las nueve de la noche, hora en que comenzó el concierto - sigue diciendo el comentarista, y lo consignamos por la gracia de la reseña-, había más de trescientas personas. El presidente de la República con sus secretarios del Despacho y el gobernador del Distrito, el ministro de Francia y otros individuos notables, formaban parte de la concurrencia (...) La elegancia formaba contraste con los adefesios de unas cuantas personas que llamaban la atención por lo ridiculo de sus trajes (...) Por una galantería que no se había usado en ningún concierto público, en cada intermedio se sirvieron helados a la concurrencia. ${ }^{14}$

El 9 de agosto tuvo lugar la segunda tertulia musical de Herz en la Lonja, pero es casi seguro que por las mismas razones no le haya proporcionado el interés económico ni de prestigio que espe-

\footnotetext{
* José Joaquín Herrera

12 El Siglo $X I X$, julio 22

13 Ibidem, julio 24.

14 El siglo XIX, agosto 9
} 
raba, así que desistió de las dos últimas progamadas en ese lugar para anunciar su presentación en el Teatro Nacional el 18 de ese mismo mes.

Un nuevo punto de discordia surgió con Bochsa, debido a que habiendo sufrido éste la cancelación por orden superior de la pieza en un acto, El ensayo, al que había puesto música -cancelación en la que tal parece que Herz tuvo no poco que ver-, pretendió contratar el Nacional para el 17, a lo que Herz se opuso terminantemente, haciendo partícipe al público mexicano de las razones de su negativa a través de una engreída manifestación que repartió en su concierto y que publicó El Siglo XIX el 18 de agosto.

La presentación de Herz en el Nacional, la primera, no pasó sin los escollos ajenos al famoso pianista. La cantante mexicana, María Jesús Cepeda y Cossio, que participaba en el concierto, "al terminar el aire de Los puritanos faltó la voz a la señorita Cossío -relata el cronista "Yo", seudónimo de Manuel Payno. Alentada por el público repitió el trozo sin mejor éxito y entonces se echó a llorar y, sostenida por el Sr. Zanini, se retiró del foro". ${ }^{15}$

El incidente provocó la burla pública de Bochsa, que asistía al concierto en calidad de espectador, y el consiguiente resentimiento de los nacionales que vieron en ello una ofensa personal.

A juzgar por las crónicas, ni la primera ni la segunda (agosto 22) actuación de Herz en el Nacional despertaron el entusiasmo y la euforia que su tercer concierto, celebrado en ese lugar el 25 de agosto, con la participación del violinista belga Franz Coenen recién llegado a México, y la razón fue la siguiente:

Cada noche -relata "Yo"--, el Sr. Herz es superior a la anterior, y el público queda doblemente complacido (...) El Sr. Herz tocó después una fantasía sobre el precioso tema irlandés La illtima rosa, y entre la música irlandesa y la francesa e italiana introdujo la música mexicana más sandunguera, más bulliciosa, más subversiva, el Jarabe. ¡Un jarabe tocado por Herz! ¿Qué profanación, qué atentado contra el buen gusto, contra la aristocracia!..., pues bien, que digan lo que quieran los hombres de buen tono, no hagáis caso, id, aunque os cueste una onza de oro, a escuchar el jarabe tocado por Herz. ¡Dios mío!, iqué variaciones tan encantadoras, qué acentos de placer tan vivos!, iqué alegría tan franca y tan ingenua! El efecto 
que produjo en la concurrencia, fue mágico. Al principio el público creyó que era Bellini o Rossini quienes hablaban en el piano, y guardó ese respetuoso silencio que indica que en todas partes del mundo se tributa al genio una veneración religiosa; pero apenas fue reconocido el jarabe nacional cuando del cielo del teatro brotó un torrente de aplausos, una tempestad de alegría que comunicó su electricidad a los palcos y al patio. Los hombres sonaban las manos, las lindas jóvenes hacían todavía otra cosa mejor, reían, y sus ojos, su fisonomía toda, expresaban el contento y la sorpresa. ¿Herz tocando el jarabe, el músico de Viena, el discípulo protegido de Napoleón, tocando un sonecito de los Tapatíos y los Poblanos? Éste es un acontecimiento notable, digno de mencionarse. Los aplausos fueron tan repetidos y las instancias del público tan vivas, que el Sr. Herz tuvo que salir de nuevo a tocar. ¿Y qué tocaría?... Bah, para un músico, para un talento, esto es cosa de poca monta. Un momento de inspiración, y el negocio está concluido. ${ }^{16}$

Corrida la voz, un público numeroso acudió al cuarto concierto (agosto 29), el más concurrido hasta entonces, y para el que, descubierta la piedra de toque, Herz había programado el Cuadro musical, triptico compuesto de una introduzion y notturno titulado Los suspiros, La rancherita, recuerdo de viaje, y el capricho brillante sobre un aire nacional, que produjo el mismo jubiloso efecio que las variaciones sobre el jarabe en el concierto anterior, de ahí que para la siguiente presentación (septiembre $1^{\circ}$ ) la pluma de "Fidel" nos haya dejado una crónica que habla por sí misma y de la que extraemos los párrafos principales:

El teatro, digo, estaba espléndido, con sus columnas blanquísimas, con la reverberación de sus quinqués, con los palcos del ayuntamiento con su cortinaje de terciopelo con fleco de oro, y su dosel elegante.

La concurrencia era numerosa, y sólo se veía en el patio un bosque de sombreros entre el humo incivil de los mil habanos que axdian: los balcones y los palcos primeros, segundos y terceros, eran otras tantas hileras y grupos de hermosuras (porque las ancianas se conservan en segundo término, dando con esto un testimonio de buen 
juicio) que brillaban de medio cuerpo, como saliendo de otras tantas nubes blancas, escarlatas, de gasa y seda, de punto y terciopelo.

Sus rostros de ángeles, sus flores naturales en el pecho, sus abanicos de levísimas y trémulas plumas en las manos, resplandeciendo con sus joyas, embriagando con sus perfumes, magnetizando con sus miradas fascinadoras.

En último término, en la Laponia teatral, en las regiones que sólo alumbra el crepúsculo, se veía una masa compacta de túnicos, fracs y capas de alborotadora concurrencia, que disputaba, se rebullía y hacía que tembláramos, temiendo que se desatase una lluvia de habitantes de la luna, amigos de la filarmonía y el buen humor.

Era un ruido indescriptible, compuesto de las mil y una conversaciones, de las risas, de los abanicos, de los bastones; era el inglés indiferente, escarlata por sus excesos gastronómicos, que hablaba un rasposo idioma, sentado en el pulmón, y dejando percibir la coronilla de su cabeza, la punta de su roja nariz y el humo de su puro; era el grupo de cócoras instalando su comisión de crédito público; era el amante, buscando de parapeto a su adorado tormento; era el tránsito y la reyerta de los acomodadores, con sus obeliscos de cojines sobre los hombros, haciendo temblar y encogerse a los que tenían cerca.

La ansiedad se comunica, el presidente llega con los señores ministros y los municipales, que es costumbre que en el palco no falten a sus deberes de urbanidad.

Los violines y los demás instrumentos se templañ (sic), dejando caer sus agudos acentos en el ruido general, y crece la algarabía; por fin estalló la obertura en medio de aquel zumbido, y el silbato, reclamando la atención, hizo volver los ojos todos al foro descubierto.

Unos cuitados romanos, al parecer, con su tunicela infantil, sus pantalones azules y sus cascos con pararrayo, ejecutaron un coro que sirvió para que pasase desapercibido el ruido importuno de las sillas que se arrastraban, de las reyertas y conversaciones que no concluían, y del tránsito de algunos concurrentes de última hora. Los descendientes de Romo y Rémulo (sic), después de abrir tanta boca, desaparecieron, y bajó el telón mientras se colocaba el piano en su lugar respectivo. 
Entre vivos aplausos apareció el Sr. Herz, que es un hombre de regular estatura, erguido, delgado, de entrecana cabellera y de maneras caballerosas.

Se colocó frente a su piano, arrojó sobre él con desembarazo sus guantes y dejó caer su mano en las teclas, como para probar su docilidad: ellas suspiraron sumisas, y tocó su Violeta.

Después de esta descripción, bella por sus detalles como un film de Visconti, "Fidel" relata cómo concluye la primera parte del programa con las intervenciones del cantante Zanini y el violinista Coenen. Siguió el intermedio y la obertura en turno...

En obsequio a la verdad, diré, que se prestó poca atención a la obertura -prosigue "Fidel"-, porque los concurrentes, con los programas en las manos, esperaban el momento de oír las improvisaciones del "Rey de los pianistas". Por otra parte, como la obertura se tocó en un intermedio, los ecos de la música se oían entre el aleteo de los abanicos y el ruido de las conversaciones. Los acomodadores en este intervalo recogían de los señores del patio los temas o sus nombres, para que el público, por sus aplausos, decidiera, cuáles eran los temas que elegía.

Alzóse el telón: a un lado del piano, en medio del foro, estaba una mesita redonda con una vela encendida.

Salió el Sr. Zanini en traje con que iba a desempeñar después "el dúo" del Barbero; anticipación en carácter no muy oportuna (risas, murmullos, señales de inquietud).

Los criados condujeron multitud de papeles, y se empezaron a leer los títulos. -La cachucha. -El público: Chut! Chut! No! No! (Se puso entre los temas no admitidos) -Marcha de la Caballería Mexicana. -Resonaron inmensos aplausos -si, si, si, muchas voces. $-E l$ Sr. Bochsa pintado por si mismo... (Risas) -El himno del riego. -Una voces si, sí, sí. Otras: No! no! nooo! Chiiist! -La pasadita. Estruendosos aplausos en las galerías y en el patio! -si, si, si. Bien! Bien! Muy bien! Por fin se separaron, además de los dos temas citados, Los enanos, El butaquito, y no recordamoś cuál otro, entre las risas, los palmoteos, los gritos de más recio y el disgusto de muchos, porque bajo el pretexto de los temas, desahogaron cobardes antipatías, como un tema contra 
el Sr. Patiño, que muestra lo fácil que es que se abuse de esa invención, convirtiendo los temas en buzón de anónimos indecentes. Creemos que la autoridad impedirá que se repita ese abuso, perpretado por algún canalla, que es la primera vez, sin duda, que concurre entre gente decente. Terminada esta gresca, que nos hizo recordar las votaciones de los meetings, se presentó entre mil aplausos el Sr. Herz, recogió los temas, los examinó, los colocó no sin dificultad sobre el atril de su piano, y se dispuso a tocar con la seguridad del triunfo.

En efecto, a las vibraciones solemnes de la Marcha mexicana, siguieron los risueños acordes de La pasadita, el público los reconoció y quiso prorrumpir en aplausos; pero se contuvo por no perder una sola de aquellas notas mágicas; después Los enanos con sus saltitos provocativos y sensuales, picarescos; luego, como columpiándose, la última armonía se reposaba para hacer brotar el carcajeo del Butaquito, con sus mil modulaciones incendiarias y festivas, luego la Marsellesa, luego... no sé, era un manantial de armonía, que todo lo llenaba; eran nuestras costumbres, eran nuestros afectos populares, ardientes como nuestro sol, expresivos como nuestro carácter, pero embellecidos: se cerraban los ojos y se veían las chinas salerosas con sus piececitos breves, con la cintura insurgente, con sus ojos revolucionarios.

Al concluir Herz, nunca más grande que cuando se dejó ver como artista creador, no fue aplauso, fue frenesí la explosión, golpeaban con los bastones, las tablas de la galería hacian rajas a golpes, todas las manos se abrían para aplaudir, todas las voces exclamaban como si fuese una sola: Bien! bien! bravo! oh! oh! bravo! En medio de aquel estrépito, cubriendo el cielo del teatro, descendió una nube de papeles; dizque con versos (los renglonatos desiguales eran en su línea de malos de primer orden). Todos los brazos se levantaban para recogerlos, se llamó a la escena al rey de los pianistas... Se presentó, y una lluvia de flores, de coronas, y de ramos, tapizaron la escena, rompió entre los aplausos una música alegrísima, oblación caballerosa de la orquesta: resonaron los vivas, y el Sr. Herz, visiblemente conmovido recogió los lauros que habia conquistado su talento sublime. (...) La noche del sábado fue una alucinación, fue un solo instante, fue una ráfaga del aura embalsamada que pasó para perderse en el vacío insondable del tiempo.

¿Glonia a los artistas!, y tú, noche que soñé despierto con una feliciudad que no alcanzaré jamás, vive siquiera una hora en esta hoja 
frágil de papel, que como la Efímera, morirá con la luz de un nuevo día!!! 17

El triunfo obtenido estimuló aún más el aspecto sensacionalista de Herz, que anunció para el 5 de septiembre un concierto "monstruo". La monstruosidad consistía en presentar como obra fuerte del programa la obertura de Guillermo Tell de Rossini, arreglada por él mismo para ocho pianos y dieciséis pianistas, espectáculo jamás visto en México y en el que alternó con pianistas de la localidad.

Los ocho pianos - dice "Yo"- tenían fija la atención del público. Llegó el momento, y se presentó Herz a la cabeza de la poderosa falange de los dieciséis pianistas |Marzán, Balderas, Aguilar, Valadés, Retis!... Sus nombres como compositores, su fama como excelentes maestros, los han hecho bastante populares, y no hay persona de México que no los conozca; así pues, su sola presencia en la escena, arrancó aplausos.

Comenzaron a tocar, y dirigidos por el Murat de esta batalla, hicieron proezas filarmónicas que nunca habíamos escuchado. Diremos, sin embargo, que el público quedaría verdaderamente sorprendido si ese Murat de la música compusiera un concierto absolutamente de aires nacionales, pues la música italiana, sublime como es, no tiene tanto eco en el corazón como las canciones de nuestro país con que hemos despertado, por decirlo así, a la vida. Convencido el Sr. Herz de que le va bien con nuestras indicaciones, juzgamos que adoptará ésta y palpará sus buenos resultados. ${ }^{18}$

Efectivamente, Herz atendió la sugerencia de Payno y finalizó el segundo "concierto monstruo" (septiembre 7) con las Variaciones brillantes y de bravura sobre la contradanza criolla $L a$ trópica para la que no hubo solamente ocho pianos y dieciséis pianistas sino una orquesta completa. La afluencia del público debió de haber sido enorme, pues en consecuencia del tráfico que se hizo en el concierto anterior con los boletos de entrada, que hubo quien compara hasta por el exorbitante precio de una onza cada uno, Herz logró que le fuera permitido disponer de sillas en el foro, anunciaba El Siglo XIX en su edición de ese día.

17 El Siglo XIX, septiembre 4

18 Ibidem, septiembre 7. 
El 11, el Teatro Nacional se transfiguró con el estreno del hermoso alumbrado de gas, y "unque nos pareció que no estaba demasiado blanco -opinaba la Redacción de El Siglo XIX-, ${ }^{19}$ sin embargo, la luz es infinitamente mejor que la del aceite", así que el último concierto del "rey de los pianistas" anunciado para la noche del 12 se revistió de un nuevo interés. Por su parte, Herz ideó concluir sus presentaciones en la capital con un programa apoteótico, pues iniciándose con la insólita inclusión de un grupo folklórico de guitarras y jaranitas "que en su línea nos parece de un mérito igual al del Sr. Bochsa" -comentó la Redacción de El Siglo XIX-, concluiría con una marcha militar mexicana compuesta por Herz y ejecutada en doce pianos por veinte profesores, doble orquesta, banda militar y coro de hombres, todos bajo su dirección. No faltó la tan exitosa improvisación sobre temas nacionales que el público eligiera, si bien con la advertencia de que:

Habiendo visto el Sr. Herz con sentimiento que en su última improvisación algunas personas se habian servido de esta diversión, tan grata en Europa, para hacer alusiones personales, se avisa que los temas que se presentaren de este modo no serán admitidos. ${ }^{20}$

El redoble de un tambor fue la señal de la salida de una compañía de soldados, que cantaron la marcha sin ser escuchados, pues el torrente de armonía hacía que no sólo se perdieran sus voces sino que se estremeciera el teatro -comentaba El Siglo XIX. Al mismo tiempo que salió el coro de guardias nacionales, aparecieron de uno y otro lado del salón que formaba el foro, multitud de banderas tricolores, que fueron saludadas con los bravos y palmoteo del público.

Éste se empeñó en que se repitiera la marcha militar, y entretanto el teatro se oscurecía visiblemente... Sonaron las doce... los últimos acentos de la música guerrera se escuchaban... entre la luz rojiza de la gloria se veían las banderas de la libertad, la oscuridad aumentaba... de improviso la lámpara, ese sol del teatro de Vergara se eclipsó enteramente... Las tinieblas envolvieron a toda la concurrencia. Así terminó la función, y cada cual bajó y salió del teatro

19 El Siglo $X I X$, septiembre 11.

20 Ibidem, septiembre 14. 
como Dios le dio a entender. La explicación de toda esta barahúnda romántica está en dos palablas: faltó el gas. ${ }^{21}$

No sería ésta la última actuación de Herz en la ciudad de México, pues invitado a participar en el beneficio a don Francisco Arbeu, promotor del alumbrado de gas en el Nacional, suspendió su viaje a Puebla previsto para el 13 de septiembre.

Pero aquel público que se había desvivido por concurrir al beneficio del compositor extranjero pagando las localidades a tres onzas de oro -advierte Olavarría-, ${ }^{22}$ no quiso asistir al de Arbeu y fuese a oír discursos y poesías a la Universidad, con motivo de las fiestas del I5 de septiembre, fecha también del malhadado beneficio.

A fines de mes, el "rey de los pianistas" inició su gira de conciertos por el interior de la República para la que, hecho insólito, el Ministerio de Guerra dirigió a las comandancias generales de Querétaxo, Guanajuato, Zacatecas y San Luis Potosí una circular ordenando facilitarle escoltas y todo lo necesario para la seguridad de su persona durante el tránsito por esos lugares, ${ }^{23}$

En Querétaro,

el Prefecto tuvo la ridícula ocurrencia de prohibir que se saliese a recibir al artista, alegando que eso alarmaría a la población supo. niendo que se trataba de un pronunciamiento. A pesar de la prohibición, había mucha gente reunida en la casa de las diligencias; y aunque se condujo muy bien, y en lo que menos pensaba era en revoluciones, se envió una guardia de que no se tenía necesidad. ${ }^{24}$

Para su primer concierto en esa ciudad, celebrado el 28 de septiembre, "no hubo asiento vacío y la concurrencia estaba de lo más entusiasmada. A cada pieza interrumpía a Herz con estrepitosos aplausos", y al concluir sus presentaciones -seis-, El Siglo XIX comentaba que:

21 El Siglo XIX, septiembre 14

22 Olavaruía, $p$.

23 El Siglo XIX, septiembre 23.

24 Ibidem, octubre 3. 
Este célebre artista ha dado sus conciertos en Querétaro sin que el teatro haya dejado de estar lleno una sola noche. No se creía por cierto que en aquella ciudad fueran tán filarmónicos. ${ }^{25}$

Dos conciertos dio el pianista en San Juan del Río, dos en Celaya y uno en San Miguel, al cabo de los cuales se dirigió a Guanajuato, ciudad que el 24 de octubre le obsequió una serenata dada por la orquesta del teatro, aumentada considerablemente por aficionados. Desde el 25 no había palcos ni lunetas para su primer concierto que se efectuaría el 28 de ese mes, si bien Herz se había presentado ya el 22 en uno privado que en honor del clero ofreció en la iglesia de San Diego. ${ }^{26}$ En los dos últimos de los once que dio en Guanajuato, interpretó la Marcha mexicana, acompañado de ocho pianos, coro, gran orquesta y banda.

"Se apoderó tal entusiasmo de los espectadores -informó El Siglo XIX-, que en ambas funciones la hicieron repetir tres veces." 27

Zacatecas, plaza en turno en el itinerario de Herz, no se quedó atrás en el recibimiento a tan célebre personaje, y una numerosa comitiva a caballo y en coches salió a su encuentro, dos orquestas tocaron varias piezas a su llegada ( 15 de diciembre) y durante el tránsito por la ciudad; en su honor se dio una serenata esa misma noche. El $1^{\text {o }}$ de enero de 1850 se verificaría su tercer concierto y las entradas a los dos anteriores habían sido más considerables aún que en Guanajuato. ${ }^{28}$

De ahí pasó a Durango, cuyo éxito y recepción debieron ser similares. Finalmente, la gacetilla de El Siglo XIX ${ }^{29}$ acusaba recibo de una misiva de Herz, en la que comunicaba que en su visita a San Francisco, en la Alta California, había obtenido triunfos cuya posibilidad estaba lejos de suponer. En menos de un mes había dado doce conciertos, y todos tan concurxidos que no hubo uno en que mucha gente se quedara sin conseguir entrada, a pesar del alto costo de la admisión. Asimismo, de acuerdo a su carta, sus planes eran dirigirse a Tepic, Guadalajara y Morelia, para volver luego a México, que llama su ciudad predilecta, si bien

25 El Siglo XIX, octubre 11

26 Ibidem, noviembre 13.

27 Ibidem, noviembre 29 .

28 Ibidem, enero $1^{\circ}, 1850$.

29 Tbidem, mayo 5. 
los realizaría a medias debido a que la epidemia del cólera se habia agudizado singularmente en Guadalajara donde las autoridades dispusieron prohibir las reuniones públicas:

Merced a algunos empeños pudo el artista californiano (sic) salvar las dificultades pero no logró desvanecer la predisposición de ánimos, así que escasísimos han sido los admiradores que fueron a tributarle aplausos a su indisputable mérito -consignaba El Daguerrotipo el 22 de junio.

No obstante, dio ocho conciertos y aún tenía la intención de ofrecer otros más con la participación de aficionados locales, pero acuciado por las circunstancias ienunció al proyecto y dio marcha atrás volviendo a Tepic para decir adiós a México, al embarcarse en San Blas xumbo a Lima. ${ }^{30}$

Uno de los resortes publicitarios de que Herz echaría mano a su llegada a México y en el que "vislumbraba pingüe negocio" -acota Olavarría-, sería la composición de un himno nacional:

Casi todas las naciones tienen uno que jamás puede oírse con indiferencia -se leía en El Siglo XIX. ${ }^{31}$ En los días de combate logra que las tropas que entran en acción se llenen de entusiasmo y que hagan prodigios de valor $(\ldots)$ Entre nosotros no existe por desgracia tal himno nacional. Sabemos que Mr. Herz tiene la idea de llenar ese hueco: piensa al efecto hacer una invitación a nuestros poetas para que formen un concurso, y escojan entre las composiciones que se presenten, la que les parezca mejor. Entonces, con vista de la letra del himno, Mr. Herz compondrá la música.

Con tal motivo, la Junta Patriótica de la ciudad de México instó a la Academia de Literatura del Colegio de San Juan de Letrán a abrir concurso el 14 de agosto de 1849 , y en sesión pública del 4 de septiembre de ese mismo año se leyó el acta en que el jurado, formado por José María Lacunza, Carpio, Pesado, Quintana Roo y Alejandro Arango y Escandón, otorgaban su voto a Andrés Davis Bradburn, con la salvedad de que siendo el himno nacional un canto surgido no del arte sino de las circunstancias y espontaneidad de un pueblo, el jurado se limitaba a calificar una composición

Bo El Daguerrotipo, julio 6.

31 Julio 24, 1849. 
"que a lo más sería la expresión de patriotismo y el testimonio del genio de su autor".

El himno de Herz no se popularizaría como tal, como a excepción del de Nunó y Bocanegra, no adquirirían rango de nacionales todos los demás que a ejemplo de Herz se compusieron a lo largo del siglo $\mathrm{xIX}$, en que la fiebre de himnos patrios cundió como verdadera enfermedad infecciosa. Terminado en noviembre de 1849, fue editado en México por el impresor Ignacio Cumplido que compró los derechos, y también Cumplido dio a luz su Wals brillante " $L a$ camelia", dedicado a una señorita mexicana, los arreglos para piano de temas populares presentados con el título de Álbum de canciones nacionales y la Polka del siglo, dedicada al periódico del que era editor. El trabajo dejó muy satisfecho al compositor, cuyo elogio máximo fue comentar que sería apreciado en el mismo París.

Ninguna de estas composiciones ha llegado a mis manos, pero en cambio otras me permiten dar al lector una idea de la música con que Herz deslumbró a nuestros antepasados. En ellas se advierte una estructura elemental, sin desarrollo sustancial del material melódico, casi siempre sujeto a variaciones ornamentales de aparente acrobacia pianística cada vez mayor, o bien variaciones rítmicas que cambian el carácter de la pieza, o sea, la melodía propuesta como tema de una canción, digamos, pasa por efecto del ritmo a ser tema de una polka, o de una cuadrilla, o de una marcha militar, para constituir de esta manera trozos de contraste rítmico. El plan armónico, muy pobre, no se modifica en estos cambios y permanece esencialmente idéntico. Finalmente, en cuanto a su estilo, pese a su contemporaneidad con Chopin, Liszt o Schumann, Herz no fue un romántico en sentido estricto del término, y deberá considerársele dentro de esa generación intermedia, de espíritu clásico, a la que perteneció Mendelssohn (1809-1847), pero sobre todo Weber (1786-1826). Establecida la debida proporción, es clara la semejanza en la música de Herz con la de este último compositor, con quien indudablemente guarda parentesco.

Conviene subrayar, para terminar, que el mérito indisputable de Herz fue el de haber consolidado en México el concierto público instrumental, en el que la música mexicana popular aspiró a la categoría que alcanzaría sólo hasta principios de este siglo, con la música de Manuel M. Ponce. 